\title{
Experimental studies on impedance based fault location for long transmission lines
}

\author{
Saeed Roostaee ${ }^{*}$ (D, Mini S. Thomas and Shabana Mehfuz
}

\begin{abstract}
In long transmission lines, the charging current caused by the shunt capacitance decreases the accuracy in impedance based fault location. To improve the accuracy of fault location, this paper presents a novel scheme, where two Digital Fault Recorders (DFRs) are installed in a line. They can send the transient data of the faults to the both ends of a line. To estimate the distance of a fault, impedance based fault location methods are applied with transient fault data of both ends protection relays and both DFRs installed in a line. To evaluate the proposed scheme, a laboratory setup has been developed. In the lab, several faults have been simulated and associated voltages and currents are injected to a relay IED to compare experimental results.
\end{abstract}

Keywords: Transmission line fault location, Impedance based fault location

\section{Introduction}

Accurate fault location can expedite the repair of the faulted components, speed-up restoration, reduce outage time. Therefore, it can improve power system reliability [1, 2]. Many methods and techniques have been introduced on fault location estimation so far. Among them, impedance based fault location methods are most used by utilities [3, 4]. Based on the input data of fault location algorithms, they can be categorized as:

- One-end $[5,6]$

- Two-end algorithms [7-9]

One-end impedance fault location method is economic and simple as compared to other fault location methods [5]. One end impedance fault locators calculate the location of a fault based on the impedance from one end of a transmission line. However, this technique is subjected to several sources of error, such as the zero sequence mutual effects, the uncertainty of parameter in transmission line, unbalanced load flow, the influence of facts devices, the accuracy of transmission line model, and measurement errors [10].

\footnotetext{
* Correspondence: saeed61850@yahoo.com

Department of Electrical Engineering, Faculty of Engineering and Technology, Jamia Millia Islamia, New Delhi, India
}

Two-end algorithms estimate the location of fault using voltage and current form both the ends of a line. Based on this technique, transient fault data must be collected and synchronized from both ends of a transmission line. The transient data faults can be reported by the protection relays or Digital Fault Recorders (DFRs) which is installed in substations. In order to have an accurate fault location, the data from both ends of a transmission line should be analyzed [8]. Therefore, in this technique, microprocessor relays (or digital fault recorders), communication facility, and analysis software are required.

Two-end algorithms are divided into two categories. One of them makes use of synchronized data, and the other one utilizes unsynchronized data. In the first category, the global positioning system (GPS) is required. The measured values form the both ends are synchronized by GPS clock $[7,8,11,12]$. The other hand, in other categories, the GPS system is not needed $[8,9]$. Thereafter, the main advantage and disadvantage of this class is lower cost of implementation and lower accuracy respectively.

The common characteristics of the fault location methods mentioned in the literature are that the most of them are applied at local and remote end values of a transmission line. However, far too little attention has been paid to the values in the transmission lines. This paper proposes a novel scheme into the fault 
location based the values at both ends as well as in transmission line. The proposed scheme has been compared with one end and two end algorithms with experimental results. The fault location algorithm, hardware and software requirement, experimental setup, and experimental results are presented in this paper.

The overall structure of the study takes the form of five sections, including this introductory section. Section two reviews impedance based fault location technique. The third and fourth sections describe and test the proposed scheme. Finally, the conclusion gives a brief summary of the findings.

\section{Impedance based fault location}

Impedance based fault location algorithms are used to estimate the location of faults on a transmission line. These methods are commonly used by utilities because of simplicity. They require current and voltage signals along with sequence impedance (Positive, negative and zero) to estimate the distance to fault location. Depending on the availability of the input signals, these algorithms can be categorized into oneend and two-end methods. Following subsection are discussed these two methods.

\subsection{One-end method}

In this technique, the ground phase voltage and current are needed. Impedance based fault location from one end data can be categorized based on the source at one end and source at two ends. Figure 1 shows the source at one end where $I_{F}=I_{A}$ and the estimated distance can be calculated from (2) [1].

$$
\begin{aligned}
& Z_{F}=\frac{U_{A}}{I_{A}}=d Z_{L}+R_{F} \\
& d=\frac{\operatorname{Im}\left(Z_{F}\right)}{\operatorname{Im}\left(Z_{L}\right)}
\end{aligned}
$$

Where $Z_{F}$ is the measured impedance from substation $A, Z_{L}$ is the impedance of the line, $R_{F}$ is the resistance of fault.

Figure 2 shows impedance fault location based on the source at two ends, where $\mathrm{I}_{\mathrm{F}}=\mathrm{I}_{\mathrm{A}}+\mathrm{I}_{\mathrm{B}}$. In these types of lines, estimated distance can be obtained from (4).

$$
\begin{aligned}
& U_{A}-d Z_{L} I_{A}-R_{F} I_{F}=0 \\
& d=\frac{\operatorname{Im}\left(\mathrm{U}_{A} \Delta I_{A}^{*}\right)}{\operatorname{Im}\left(\mathrm{Z}_{L} I_{A} \Delta I_{A}^{*}\right)}
\end{aligned}
$$

Where star denotes conjugation and $\Delta \mathrm{I}_{\mathrm{A}}$ can be obtained with the following equation [1]:

$$
\Delta I_{A}=\frac{(1-d) \mathrm{Z}_{\mathrm{L}}+Z_{B}}{Z_{A}+Z_{L}+Z_{B}} I_{F}
$$

\subsection{Two-end method}

In two ends impedance based fault location, as the same fault happened in a line, the voltage in fault point should be equal. In the other words:

$$
U_{F i}^{A}=U_{F i}^{B}
$$

The voltage of fault from each end can be obtained from (6) [1].

$$
\begin{aligned}
& U_{F i}^{A}=\cosh \left(\gamma_{i} d l\right) U_{A i}-\sinh \left(\gamma_{i} d l\right) Z_{C i} I_{A i} \\
& U_{F i}^{B}=\cosh \left(\gamma_{i}(1-d) l\right) U_{B i}-\sinh \left(\gamma_{i}(1-d) l\right) Z_{C i} I_{B i}
\end{aligned}
$$

Where $\mathrm{U}_{\mathrm{Ai}}$ and $\mathrm{U}_{\mathrm{Bi}}$ are the ith symmetrical components of voltage in $A$ and $B$ respectively, $\mathrm{I}_{\mathrm{Ai}}$ and $\mathrm{I}_{\mathrm{Bi}}$ are the ith symmetrical components of current in substation $A$ and substation $B$ respectively, where can be obtained in the both ends of a line. To simplify equations, following trigonometric identities are applied.

$$
\begin{aligned}
& \cosh \left(\gamma_{i}(1-d) l\right)=\cosh \left(\gamma_{i} l\right) \cosh \left(\gamma_{i} d l\right)-\sinh \left(\gamma_{i} l\right) \sinh \left(\gamma_{i} d l\right) \\
& \sinh \left(\gamma_{i}(1-d) l\right)=\sinh \left(\gamma_{i} l\right) \cosh \left(\gamma_{i} d l\right)-\cosh \left(\gamma_{i} l\right) \sinh \left(\gamma_{i} d l\right)
\end{aligned}
$$

To estimate the location of the fault based on two end values, following formula can be derived from (6) and (7) [1].

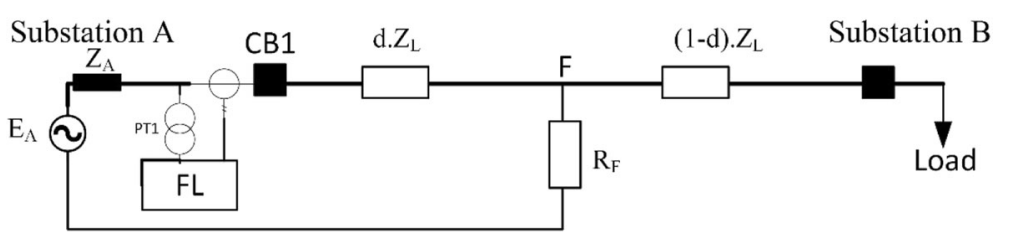

Fig. 1 Impedance based fault location with the source at one end 


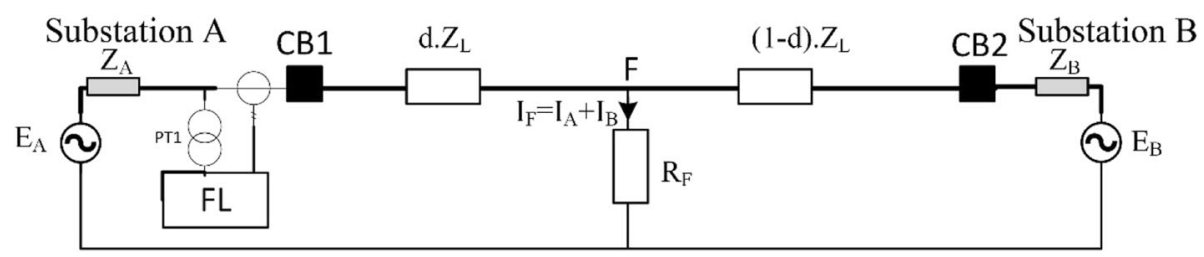

Fig. 2 Impedance based fault location with the source at two ends

$$
d=\frac{1}{\gamma_{i} l} \tanh ^{-1}\left(\frac{\cosh \left(\gamma_{i} l\right) \mathrm{U}_{B i}-Z_{C i} \sinh \left(\gamma_{i} l\right) \mathrm{I}_{B i}-\mathrm{U}_{A i}}{\sinh \left(\gamma_{i} l\right) \mathrm{U}_{B i}-Z_{C i} \cosh \left(\gamma_{i} l\right) \mathrm{I}_{B i}-\mathrm{Z}_{C i} \mathrm{I}_{A i}}\right)
$$

Where $\gamma_{i}$ is propagation constant of the line for the $\mathrm{i}$-th symmetrical component, $\mathrm{Z}_{\mathrm{Ci}}$ is the characteristic impedance of the line for the $\mathrm{i}$-th symmetrical component.

\section{Proposed scheme}

Generally, a fault location algorithm uses the recorded transient data from the protection relays at the both ends of a line. In this study, to analysis fault location, we have proposed the use of transient data of the protection relays in substations as well as transient data of the DFRs. As it is shown in Fig. 3, the DFRs are installed in a transmission line and they can send data to the both substations through a communication channel.

There is now available fibre-optic current and voltage transducers (OCT \& OVT). Where they can be combined in a light-weight and compact single phase unit with an optical metering unit (OMU). The reduced size and increased accuracy of these optical technology make the design particularly well suited to the proposed scheme. As the transducers have small size and lightweight, they can be mounted between two insulator strings in a tower. And OMU and DFR can be mount in the tower, other mounting options are possible. Under these conditions, low-cost fault location has become feasible.

Figure 4 illustrates the experimental setup for fault location. In this setup, we can simulate faults in a transmission line in PSCAD; after that, the transient data for the fault is sent to a secondary test kit to generate three phase's fault voltage and current. These three phase signals are connected to a protection relay throughout wiring. Therefore, in this setup, several faults can be simulated and the signals can be generated to provide real values for fault location functions.

Based on this setup, various types of faults in different locations of a transmission line can be simulated via PSCAD (Fig. 5). These faults generate transient data. Transient data can describe the voltage and current signals both before and after the fault. There is a component in PSCAD which can record the transient data in the COMTRADE format. This format is an IEEE standard format for recording transient data and it can be used to different fault analysis tools [13]. The CMC 256 is a test set which can play transient data. The Trans View play is software which can load COMTRADE file and generate corresponding three phase signals (Fig. 6). The signals can be utilized by protection relays to test a fault location algorithm.

\section{Results and Discussion}

To evaluate the performance of the proposed scheme, various fault scenarios are carried out by utilizing the

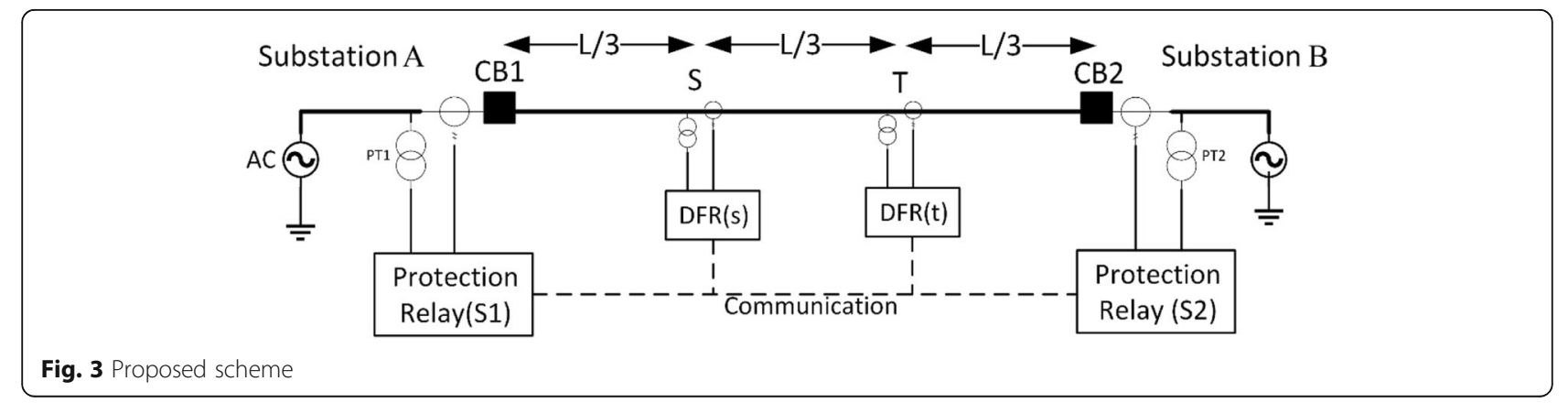




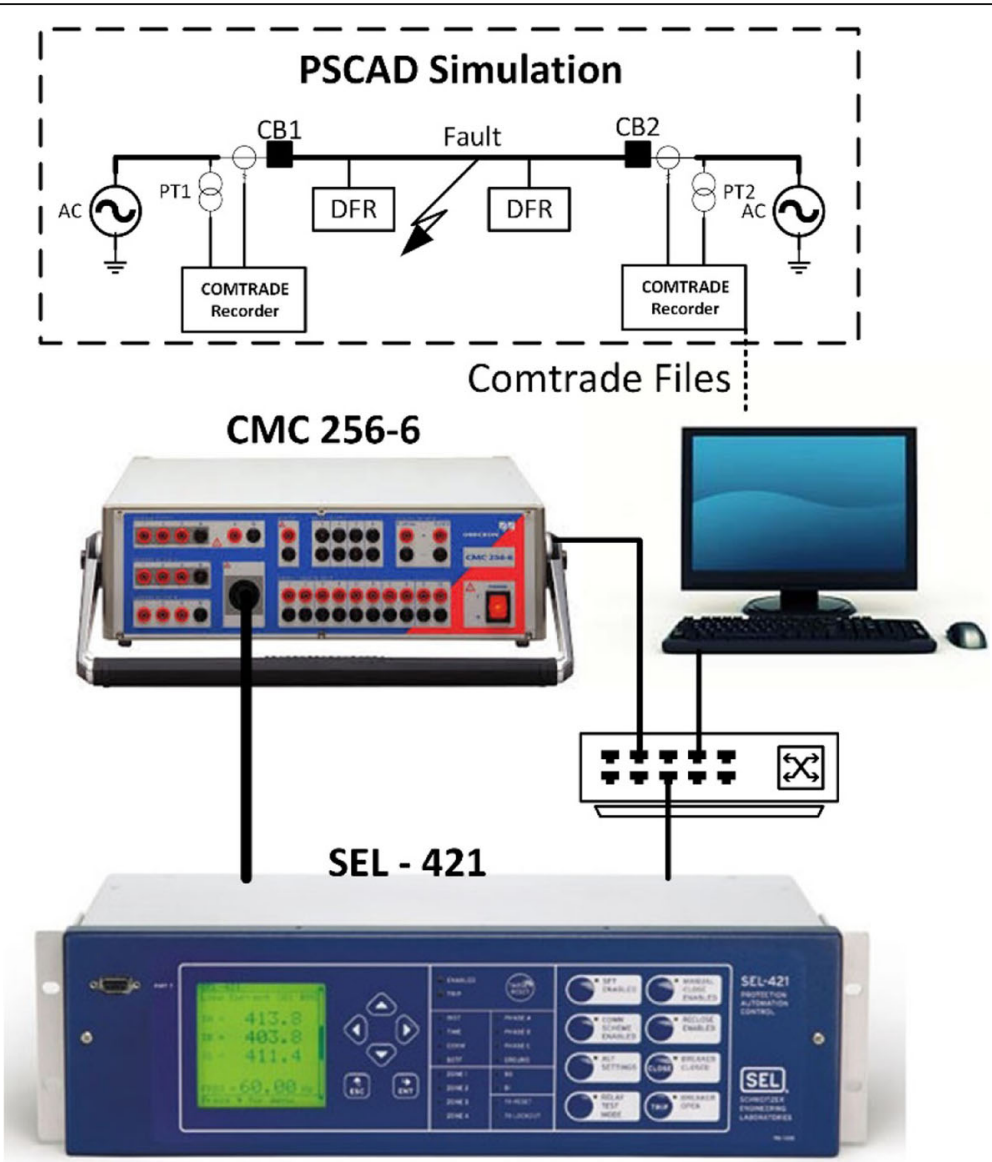

Fig. 4 Experimental setup

hardware implementation in a laboratory environment. To test the proposed scheme, we simulate a long transmission line between substation 1 and substation 2 which is a homogeneous and untransposed line. In this study, standard tower, conductor, and ground wire for $400 \mathrm{Kv}$ are selected. Figure 7 shows the main feature of the HS10 tower which is applied in this paper. To transfer the power, each phase contains four conductors in symmetrical bundle mode with $45.72-\mathrm{cm}$ space between two connected conductors. To protect the line against lightening as well as communication purpose, OPGW-24B1/70 is selected as the ground wire. The main feature of conductor and ground wire are summarized in Table 1.

Modelling of a transmission line is very important in fault location algorithms. Impedance based fault location technique estimates the location of a fault by comparison of impedance with the line impedance. Therefore, the accuracy of this technique highly depends on the accuracy of line parameter model. In this study, we used distributed transmission line model. Transmission line parameters can be calculated based on the Carson's'

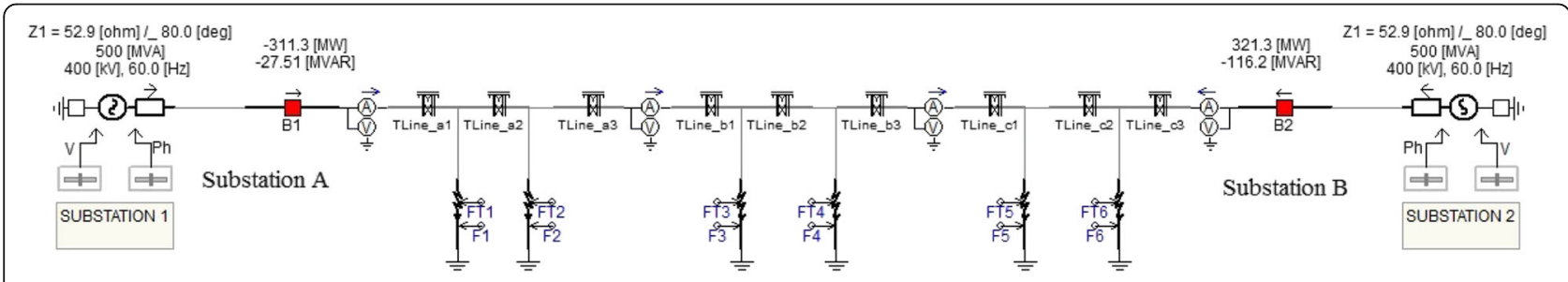

Fig. 5 PSCAD Simulation 


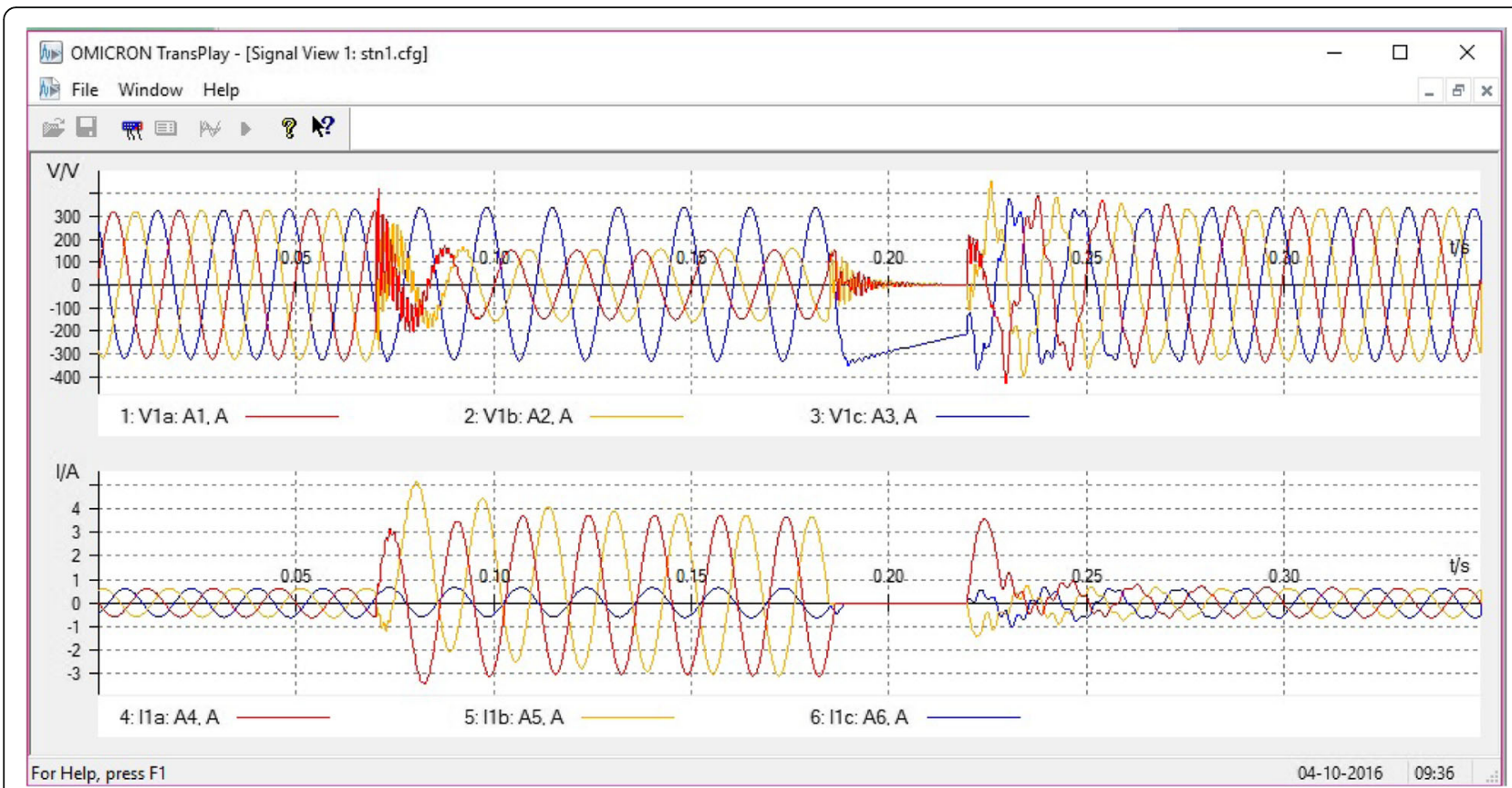

Fig. 6 Trans-View play

equations [14] and the characteristics of the tower, conductor, and ground wire. Following RLC as well as positive and zero sequences of resistance and inductance were calculated in our study as below:

$$
\begin{aligned}
& R=\left(\begin{array}{ccc}
0.038906 & 0.02464 & 0.024644 \\
0.02464 & 0.038614 & 0.02464 \\
0.024644 & 0.02464 & 0.038906
\end{array}\right) \\
& \Omega / \mathrm{km}
\end{aligned}
$$

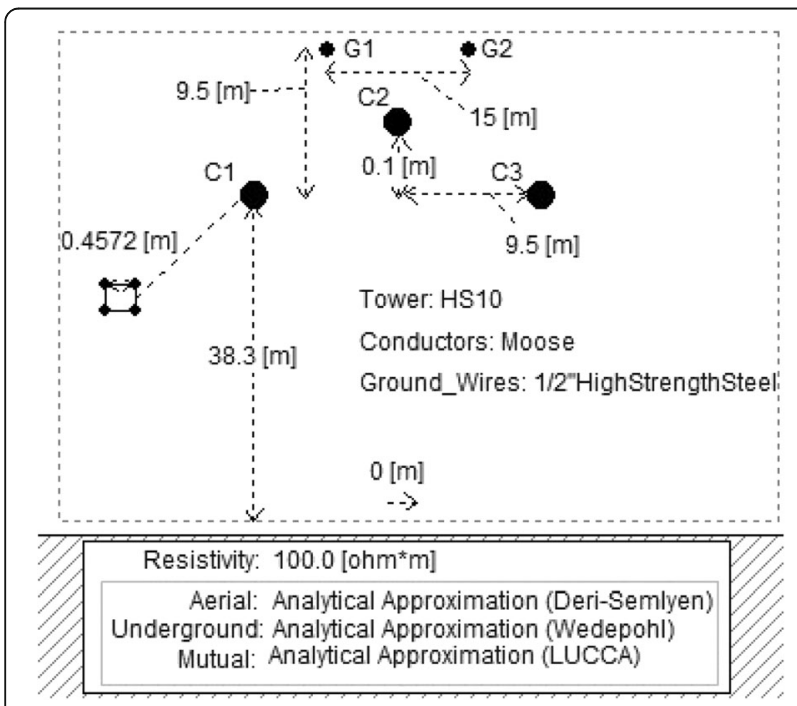

Fig. 7 400kV transmission line tower

$$
\begin{aligned}
& L=\left(\begin{array}{ccc}
0.0013674 & 0.00053991 & 0.00041175 \\
0.00053991 & 0.0013513 & 0.00053991 \\
0.00041175 & 0.00053991 & 0.0013674
\end{array}\right) \\
& H / k m \\
& C=\left(\begin{array}{ccc}
1.0871 e-8 & -2.734 e-9 & -1.0124 e-9 \\
-2.734 e-9 & 1.1534 e-8 & -2.734 e-9 \\
-1.0124 e-9 & -2.734 e-9 & 1.0871 e-8
\end{array}\right) \\
& F / k m
\end{aligned}
$$

$$
\begin{aligned}
& {\left[\begin{array}{ll}
R 1 & R 0
\end{array}\right]=\left[\begin{array}{ll}
0.014167 & 0.088091
\end{array}\right] \Omega / \mathrm{km}} \\
& {\left[\begin{array}{ll}
L 1 & L 0
\end{array}\right]=\left[\begin{array}{ll}
0.00086486 & 0.0023564
\end{array}\right] \mathrm{H} / \mathrm{km}}
\end{aligned}
$$

Following subsections contain the result under different conditions.

\subsection{Fault near mid-point}

This subsection discusses the faults between the $\mathrm{S}$ and $\mathrm{T}$ points in the line (Fig. 3). Therefore, a transient fault with following features is implemented in PSCAD.

- Fault Location: $125 \mathrm{~km}$

- Fault type: AB-g (A-B-G)

Table 1 Conductor and ground wire

\begin{tabular}{llll}
\hline Name & Application & $\begin{array}{l}\text { Diameter } \\
\mathrm{mm}\end{array}$ & $\begin{array}{l}\mathrm{RDC}\left(20^{\circ} \mathrm{C}\right) \\
\Omega / \mathrm{km}\end{array}$ \\
\hline ACSR- Moose & Conductor & 31.77 & 0.0547 \\
OPGW-24B1/70 & Ground cable & 12 & 0.79 \\
\hline
\end{tabular}




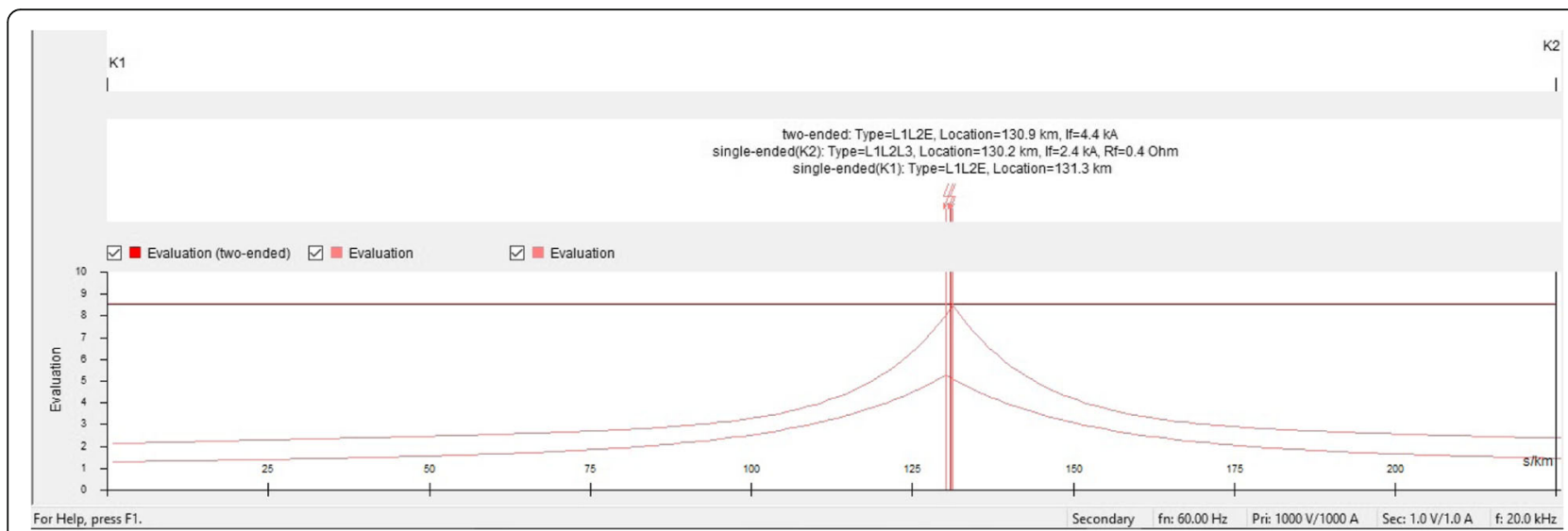

Fig. 8 Both ends fault location

- Fault Start: $0.22 \mathrm{~s}$

- Fault duration: $0.15 \mathrm{~s}$

- Fault Resistance: $0.001 \Omega$

The transient data for the above fault is analysed in OMICRON-Trans View software. As shown in Fig. 8, a screen capture of the software, the estimation of 130.9 $\mathrm{km}$ far from substation 1 is the estimation of the location of the fault.

Online relay fault location is also utilized to estimate the fault location. Three phase voltage and current signals associated with the fault are generated by the CMC 256-6. These signals are connected to the SEL-421 relay. The SEL-421 is a transmission line relay and it has five zones of phase and ground. This relay has online fault location and after any fault in a transmission line, the estimation of fault location is shown in relay' LCD as well as, the transient fault data along with estimated fault location are recorded as an event in the relay. The setting of the relay is important in fault location function. Based on the data of the transmission line following settings had been set in the relay:
- Frequency: $60 \mathrm{~Hz}$

- Line Length: 225

- Positive Impedance Magnitude: 73.4

- Positive Impedance Angle: 87.51

- Zero Impedance: 200.76

- Zero Impedance Angle: 84.3

After injection of transient data of the fault to the relay by CMC 256, the relay issues a trip signal and record the transient data of the fault (Fig. 9). The relay detects an AB-g fault in zone one. Thereafter, online relay fault location estimates a fault on $135.38 \mathrm{~km}$ far from substation 1 (Fig. 10).

In the proposed scheme, recorded event of DFR1 and DFR2 are utilized to estimate the fault location. Based on the proposed scheme which is described in section 2, a transmission line is divided into three sections. Section one is between substation A and DFR1. Section two is between DFR1 and DFR2. And the last section in between DFR2 and substation B. For the forehead mentioned fault, only section two has detected the fault. The estimation of the location of the fault is $49.8 \mathrm{~km}$ far from

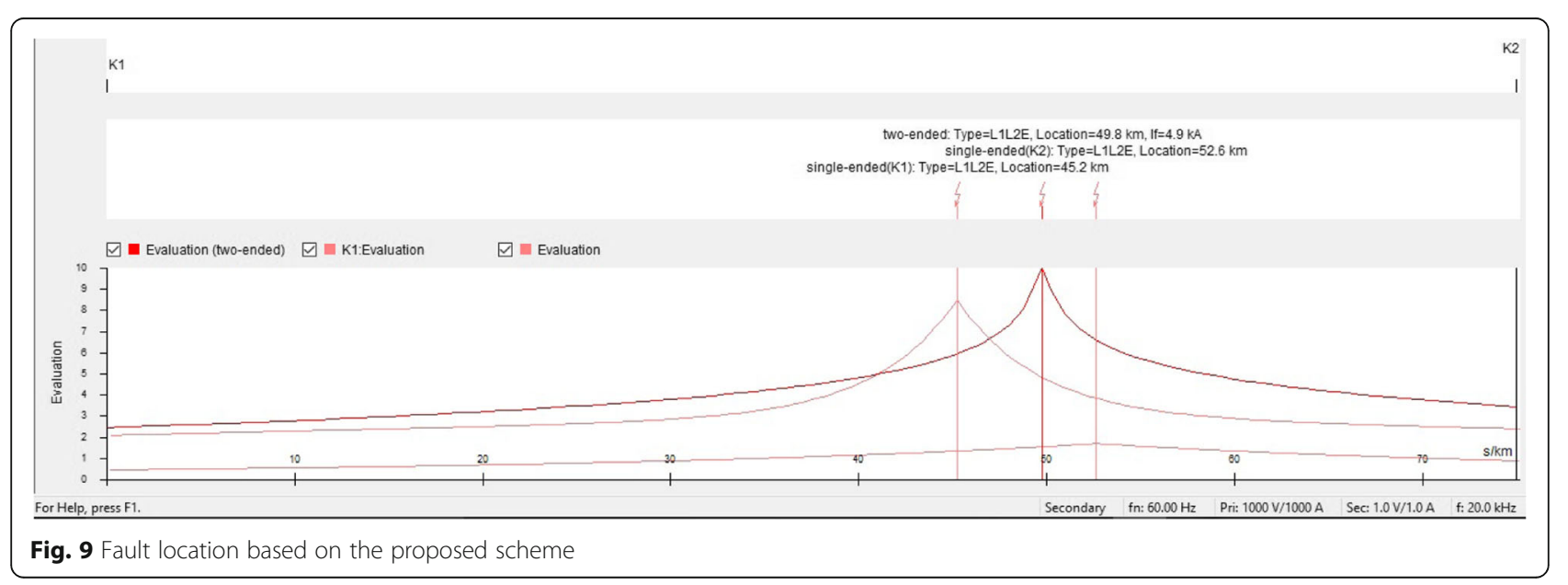




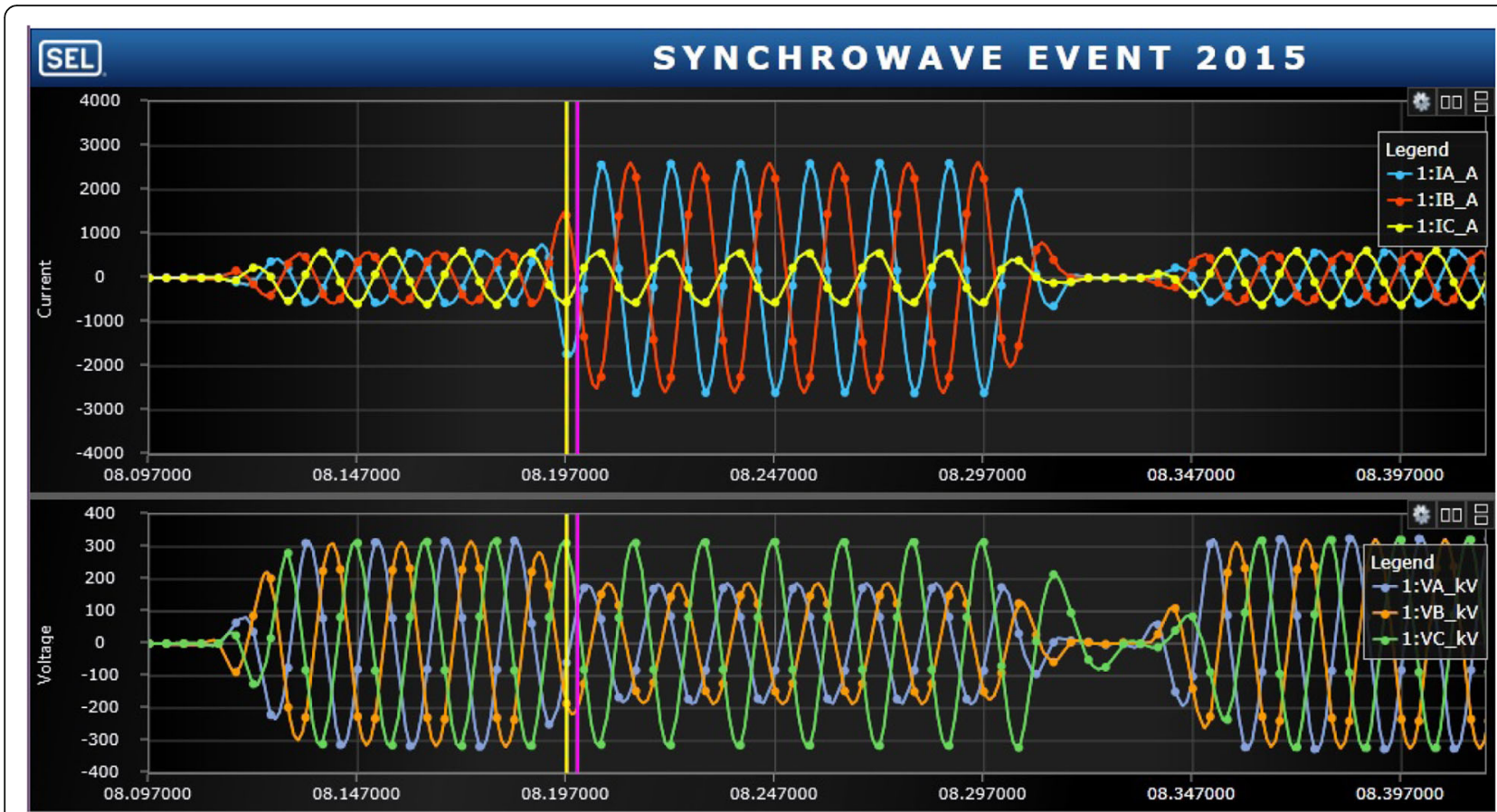

Fig. 10 Relay transient data record

DFR1 (Fig. 11). In the other words, the estimated location is $124.8 \mathrm{~km}$ far from the substation one.

To compare the accuracy of fault location based on different methods, the percentage error is determined as:

$$
\% \text { Error }=\frac{L_{\text {Estimation }}-L_{\text {Actual }}}{L_{\text {Line }}} * 100
$$

Where $\mathrm{L}_{\text {Estimation }}$ is the estimated location given by fault location algorithm, $\mathrm{L}_{\text {Actual }}$ is the actual location of the fault and $\mathrm{L}_{\text {Line }}$ is the length of the line.

Different factors affecting the accuracy of fault location. Generally, the main factors considered as: fault type and location; fault resistance; power flow; source impedance; line parameter; transient and steady errors of measurement system (including CT saturation), etc.

To improve the fault-location estimation, it is important to reduce errors based on the analysed method. As different input signals are used in the proposed scheme, the accuracy of measuring systems and CT saturation appear important. Therefore, it is suggested to apply optical measurement transformers where they have high accuracy for high voltage system. And regarding to the CTs saturation, the elimination of this source of errors can be achieved by using such a set of fibre optic measurements that are inherently free of magnetic saturation, making them ideal for capturing fast transient currents, and short circuit currents. Otherwise, the sophisticated compensation algorithms aimed at faithful reproduction of the CT primary current have to be applied. The accuracy of different techniques for the fault which is simulated in this subsection can be summarized in Table 2 .

Based on this experiment, it is observed that the proposed technique is 29 and 51 times more accurate than two end method and relay function based fault location method respectively. A similar observation can be archived for other faults, which is summarized in the Table 3.

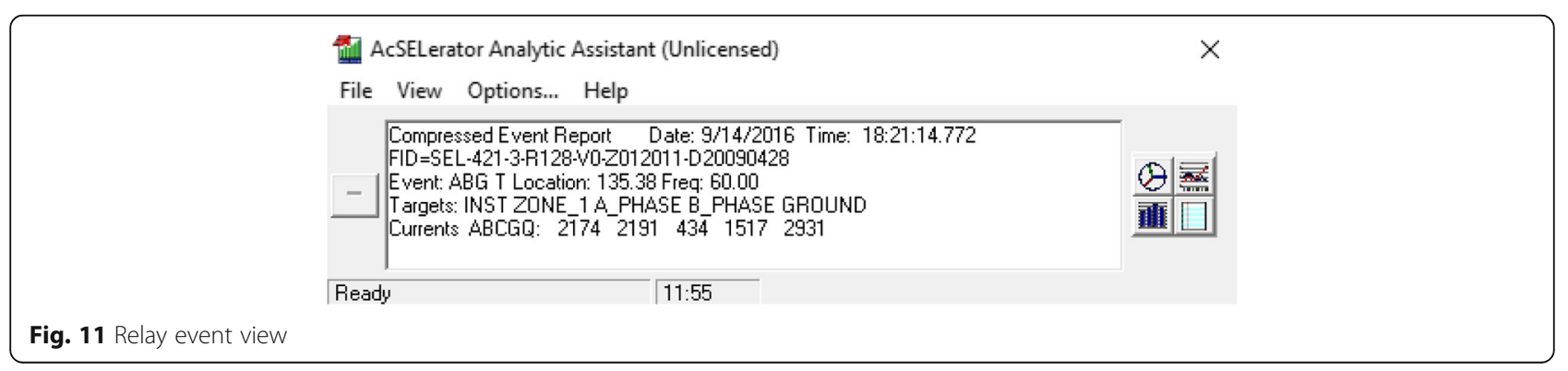


Table 2 Comparison of accuracy with different fault location method

\begin{tabular}{lllccc}
\hline Fault & $R_{\text {Fault }}$ & Location & \multicolumn{3}{l}{ Fault Location Error (\%) } \\
\cline { 4 - 6 } Type & $\Omega$ & $\mathrm{km}$ & $\begin{array}{l}\text { With two } \\
\text { ends method }\end{array}$ & $\begin{array}{l}\text { Relay Fault } \\
\text { Location } \\
\text { Function }\end{array}$ & $\begin{array}{l}\text { With the } \\
\text { proposed } \\
\text { shceme }\end{array}$ \\
\hline AB-G & 0 & 125 & 2.6222 & 4.6133 & -0.089 \\
\hline
\end{tabular}

\subsection{Fault near substations}

This subsection discusses the faults near substations. In the other words, faults between substation $\mathrm{A}$ and point $\mathrm{S}$ and point $\mathrm{T}$ and substation $\mathrm{B}$. In this condition, with failure of the measurement system in a substation, both ends methods cannot be applied. Thereafter, the measured values from the remote end can estimate the fault location with one-end algorithms. Whereas, in the proposed scheme, transient data of DFR installed in the line can be applied to obtain the desire objective.

To evaluate the proposed scheme, several faults with different locations, types, and resistances have been simulated. Testing of various fault location techniques are carried out by utilizing the hardware implementation in a laboratory environment. The result obtained from the preliminary analysis of the accuracy of different techniques are summarised in the Table 4.

Based on this experiment, it is observed that the proposed technique is more accurate than one-end fault location based measured values in substation.

Table 3 Comparison of accuracy of different fault between $\mathrm{S}$ and $T$

\begin{tabular}{llllrl}
\hline $\begin{array}{lllll}\text { Fault } \\
\text { Type }\end{array}$ & $\begin{array}{l}R_{\text {Fault }} \\
\Omega\end{array}$ & Location & \multicolumn{4}{l}{ Fault Location Error (\%) } \\
\cline { 4 - 6 } & & With two & $\begin{array}{l}\text { Relay Fault } \\
\text { ends method } \\
\text { Location } \\
\text { Function }\end{array}$ & $\begin{array}{l}\text { With the } \\
\text { proposed } \\
\text { shceme }\end{array}$ \\
\hline AB & 0 & 100 & 3.4222 & 5.1733 & 0.2222 \\
AB & 0 & 125 & 2.7111 & 4.8311 & 0.0444 \\
AB & 50 & 100 & 3.3333 & 4.9333 & 0.6667 \\
AB & 50 & 125 & 2.6222 & 4.6133 & -0.089 \\
ABG & 0 & 100 & 3.3333 & 4.9333 & 0.6667 \\
ABG & 0 & 125 & 2.6222 & 4.6133 & -0.089 \\
ABG & 50 & 100 & 3.2444 & 139.2133 & 0 \\
ABG & 50 & 125 & 2.5333 & 143.2489 & -0.356 \\
BG & 0 & 100 & 3.1111 & 6.6488 & 0.6667 \\
BG & 0 & 125 & 2.2667 & 7.1155 & -0.622 \\
BG & 50 & 100 & 2.8444 & 8.8933 & 0.3556 \\
BG & 50 & 125 & 2.1333 & 10.6889 & 0.3556 \\
\hline
\end{tabular}

Table 4 Comparison of accuracy of different fault between $T$ and Substation B

\begin{tabular}{lllcc}
\hline $\begin{array}{l}\text { Fault } \\
\text { Type }\end{array}$ & $\begin{array}{l}R_{\text {Fault }} \\
\Omega\end{array}$ & $\begin{array}{l}\text { Location } \\
\text { km }\end{array}$ & \begin{tabular}{l} 
Fault Location Error (\%) \\
\cline { 4 - 5 } $\begin{array}{l}\text { One-end Function } \\
\text { Location }\end{array}$
\end{tabular} & $\begin{array}{l}\text { With the proposed } \\
\text { shceme }\end{array}$ \\
\hline AB & 0 & 175 & 4.4888 & 0.3111 \\
AB & 0 & 200 & 4.5066 & -0.089 \\
AB & 50 & 175 & 9.9644 & 0.8 \\
AB & 50 & 200 & 12.44 & 0.2667 \\
ABG & 0 & 175 & 2.24 & 0.5778 \\
ABG & 0 & 200 & 4.4044 & 0.2222 \\
ABG & 50 & 175 & 191.87 & 0.8 \\
ABG & 50 & 200 & 228.4 & -0.089 \\
BG & 0 & 175 & 8.2133 & 0.7111 \\
BG & 0 & 200 & 8.7911 & 0.2222 \\
BG & 50 & 175 & 17.1289 & 0.4 \\
BG & 50 & 200 & 23.3778 & 0.4 \\
\hline
\end{tabular}

\section{Conclusion}

Recent development in electronic instrument transformer and communication technology provides new facility for power system functions. This paper has outlined a new fault location scheme for long transmission lines with the use of the event recorded by two DFRs which is installed in a transmission line. Preliminary analysis of testing the proposed fault locating scheme has shown satisfactory performance and a higher accuracy.

The proposed scheme can be utilized for other purposes such as protection functions. In future work, we intend to evaluate a similar scheme in protection applications.

\section{Authors' contributions}

SR: Hardware implementation, writer. MST: Technical editor, analysis of power system part, analysis of transient data. SM: Technical editor, network configurator. All authors read and approved the final manuscript.

\section{Competing interests}

The authors declare that they have no competing interests.

Received: 8 November 2016 Accepted: 31 March 2017

Published online: 26 April 2017

\section{References}

1. Saha, M. M., Izykowski, J. J., \& Rosolowski, E. (2009). Fault location on power networks: Springer Science \& Business Media.

2. Kezunovic, M. (2011). Smart fault location for smart grids. IEEE Transactions on Smart Grid, 2, 11-22.

3. Schweitzer, E. O., Guzman, A., Mynam, M. V., Skendzic, V., Kasztenny, B., \& Marx, S. (2016). Protective relays with traveling wave technology revolutionize fault locating. IEEE Power and Energy Magazine, 14, 114-120.

4. Zimmerman, K., \& Costello, D. (2005). Impedance-based fault location experience. In 58th annual conference for protective relay engineers, 2005 (pp. 211-226)

5. Kawady, T., \& Stenzel, J. (2003). A practical fault location approach for double circuit transmission lines using single end data. IEEE Transactions on Power Delivery, 18, 1166-1173. 
6. Izykowski, J., Rosolowski, E., \& Saha, M. M. (2004). Locating faults in parallel transmission lines under availability of complete measurements at one end. IEE Proceedings-Generation Transmission and Distribution, 151, 268-273.

7. Izykowski, J., Rosolowski, E., Balcerek, P., Fulczyk, M., Saha, M.M., (2011). Fault location on double-circuit series-compensated lines using two-end unsynchronized measurements. IEEE transactions on power delivery, 26(4), pp.2072-2080

8. Dutta, P., Esmaeilian, A., \& Kezunovic, M. (2014). Transmission-line fault analysis using synchronized sampling. Power Delivery IEEE Transactions on, 29, 942-950.

9. de Pereira, C. E. M., \& Zanetta, L. C. (2011). Fault location in multitapped transmission lines using unsynchronized data and superposition theorem. Power Delivery IEEE Transactions on, 26, 2081-2089.

10. Kang, N., Chen, J. and Liao, Y., (2015). A fault-location algorithm for seriescompensated double-circuit transmission lines using the distributed parameter line model. IEEE Transactions on Power Delivery, 30(1), pp.360-367.

11. Tzu-Chiao, L., Pei-Yin, L., \& Chih-Wen, L. (2014). An algorithm for locating faults in three-terminal multisection nonhomogeneous transmission lines using synchrophasor measurements. Smart Grid, IEEE Transactions on, 5, 38-50.

12. Dobakhshari, A.S. and Ranjbar, A.M., (2015). A novel method for fault location of transmission lines by wide-area voltage measurements considering measurement errors. IEEE Transactions on Smart Grid, 6(2), pp.874-884.

13. IEEE Draft Standard for Common Format for Transient Data Exchange (COMTRADE) for Power Systems, IEEE PC37.111/D4, January 2012 (IEC 60255-24 Ed.2), pp. 1-72, 2012.

14. Carson, J. R. (1926). Wave propagation in overhead wires with ground return. Bell System Technical Journal, 5, 539-554.

\section{Submit your manuscript to a SpringerOpen ${ }^{\circ}$ journal and benefit from:}

- Convenient online submission

- Rigorous peer review

Immediate publication on acceptance

- Open access: articles freely available online

- High visibility within the field

- Retaining the copyright to your article

Submit your next manuscript at $\gg$ springeropen.com 